\title{
Depression and anxiety among patients with Parkinson's disease: frequency, risk factors, and impact on quality of life
}

\author{
Eman M. Khedr ${ }^{1,2^{*}}$, Ahmed A. Abdelrahman', Yasser Elserogy ${ }^{1}$, Ahmed Fathi Zaki ${ }^{3,4}$ and Ayman Gamea ${ }^{3,4}$
}

\begin{abstract}
Background: Depression and anxiety are non-motor symptoms of Parkinson's disease (PD) that are often overlooked and underrated. This study aimed to highlight the frequency and risk factors of depression and anxiety among subjects with PD.

Methods: Sixty-four patients with PD who were diagnosed according to United Kingdom Parkinson's Disease Society (UKPDS) Brain Bank Criteria and 50 sex- and age-matched healthy control subjects are evaluated for depression and anxiety. PD severity and staging were assessed using Unified Parkinson's Disease Rating Scale (UPDRS) and Hoehn and Yahr scale. Depression and anxiety were diagnosed using DSM-IV TR criteria and scored using Hamilton Depression and Hamilton Anxiety Rating Scales (HAM-D and HAM-A). The World Health Organization Quality of Life (WHOQOL)-BREF was used to assess impact of depression and anxiety on quality of life.

Results: $31.25 \%$ of patients with PD had depression while $40.6 \%$ of patients had anxiety disorder. Depression was higher in females and patients with history of depression and low socioeconomic status (SES). Anxiety was common in young patients and those who had history of anxiety. Overlap between depression and anxiety was recorded in 23.4\%. Total UPDRS and Hoehn and Yahr scale accounted for 33.4\% of variance for depression. Total UPDRS and earlier age of onset accounted for $39 \%$ of variance for anxiety. Advanced disease stage and severity were independent predictors for depression while disease severity and younger age of onset were the main predictors for anxiety. Depression and anxiety have a negative impact on the overall quality of life of PD patients especially on physical and psychosocial domains.

Conclusion: Depression and anxiety are relatively common in PD. Female gender, low SES, and history of depression were the main risk factors for developing depression. Young age and history of anxiety were risk factors for anxiety. Both had negative impact on quality of life.
\end{abstract}

Keywords: Frequency, Parkinson's disease, Unified Parkinson's disease rating scale, Depression, Anxiety, Quality of life, Hamilton depression rating scale, Hamilton anxiety rating scale

\footnotetext{
* Correspondence: emankhedr99@yahoo.com

'Department of Neuropsychiatry, Faculty of Medicine, Assiut University

Hospital, Assiut, Egypt

${ }^{2}$ Neuropsychiatric Department, Faculty of Medicine, Aswan University

Hospital, Aswan, Egypt

Full list of author information is available at the end of the article
}

\section{Springer Open}

(c) The Author(s). 2020 Open Access This article is licensed under a Creative Commons Attribution 4.0 International License, which permits use, sharing, adaptation, distribution and reproduction in any medium or format, as long as you give appropriate credit to the original author(s) and the source, provide a link to the Creative Commons licence, and indicate if changes were made. The images or other third party material in this article are included in the article's Creative Commons licence, unless indicated otherwise in a credit line to the material. If material is not included in the article's Creative Commons licence and your intended use is not permitted by statutory regulation or exceeds the permitted use, you will need to obtain permission directly from the copyright holder. To view a copy of this licence, visit http://creativecommons.org/licenses/by/4.0/. 


\section{Introduction}

Parkinson's disease (PD) is a neurodegenerative movement disorder in which bradykinesia in combination with rest tremors, rigidity, or both is the main motor symptoms of the disease [1]. Mood disorders are the most prevalent non-motor symptoms (96.4\%) of studied Egyptian patients with PD [2]. Depression and anxiety are among the most distressing neuropsychiatric symptoms of PD [3]. These symptoms represent a further burden on the patients and their caregivers [4]. These non-motor symptoms are often overlooked and do not take an adequate concern or proper treatment plan [5]. Prevalence of depression in PD exceeds that in other disabilities of the same degree [6]. The symptom overlap between depressive disorders and PD increases the difficulty of detection of depression among such patients and necessitates a high index of suspicion [7]. Psychiatric disorders in PD are likely the result of complex interactions between genetic vulnerabilities, cognitive predisposition, age-associated changes in neurobiology, and stressful events. Deficiencies in dopaminergic, serotonergic, and cholinergic networks have all been suggested to play a role in pathobiology [8-10]. The disease's multisystem nature makes it difficult to identify the specific causes of neuropsychiatric disorders mainly depression and anxiety. Estimating the frequency of depression and anxiety and understanding factors of their association in PD may facilitate early detection and add future treatment strategies. In this study, we are aiming at highlighting the frequency and predictors of depression and anxiety among PD patients.

\section{Methods}

In this cross-sectional study, we recruited 64 patients with Parkinson's disease from the neurology outpatient clinic of our hospitals from September 2015 to August 2016; they were compared with a group of 50 age- and sex-matched control subjects. Inclusion criteria included patients diagnosed with PD according to the United Kingdom Parkinson's Disease Society (UKPDS) Brain Bank Criteria $[11,12]$, non-demented, willing to participate in the study, and able to give informed consent. Exclusion criteria included moderate to severe dementia as measured by Mini-Mental State Examination (MMSE) test with a score of $<18$ for literate patients and $<16$ for illiterate patients $[13,14]$. Severe hearing or visual impairment or severe general medical problems (renal or liver failure as these are confounding factors related to depression). Neither the patient nor controls have been treated with antidepressant nor anxiolytic drugs. All participants provided an informed written consent. The local Ethical Committee of Qena Faculty of Medicine approved the study.
Modified Hoehn and Yahr scale [15] and Unified Parkinson's Disease Rating Scale (UPDRS) [16] were used for staging and detection of severity of $\mathrm{PD}$, respectively. Socioeconomic scale for family was used for socioeconomic assessment [17].

Structured Clinical Interview for DSM-IV-Clinician Version (SCID-CV) [18] the Arabic form [19] was used to diagnose depression and anxiety, as well as to eliminate any clinical comorbidity in patients and controls. It has seven diagnostic modules for disorders in the axis I.

An Arabic validated version of Hamilton rating scale for depression and anxiety (HAM-D and HAM-A) was used to score the severity of depressive and anxiety symptoms [20, 21]. The cutoff point for HAM-D was 7, and above it, different grades of severity have been diagnosed [22]. The cutoff point for HAM-A was 13, and above it, clinically significant anxiety has been diagnosed [23]. Patients with "on/off" complications were assessed during "on" states according to the recommendation of Movement Disorders Society Task Force [24].

An Arabic validated version of the World Health Organization Quality of Life (WHOQOL)-BREF [25] was used to assess quality of life for all patients included in the study. It has 26 items on a 5-point Likert scale, which includes two global items about QOL and health and 24 items relating to four domains of QOL. The two general questions are about an individual's overall perception of quality of life and health. The four domain scores are scaled in a positive direction (i.e., higher scores denote higher quality of life).

\section{Statistical analysis}

The data were analyzed using SPSS 16.0 software. Qualitative data were described in frequency using percentage (\%). Continuous variables were expressed in mean \pm standard deviation (SD). Comparative statistical analysis between variables was done using chi-square for qualitative data and independent $t$ test for continuous variables. A value of $P<0.05$ was considered statistically significant. Pearson's rank correlation coefficients were calculated to assess the direction and magnitude of association between variables in relation to depression and anxiety. A hierarchical multivariable regression analysis was performed, with variables being entered into the model according to the magnitude of correlation.

\section{Results}

\section{Socio-demographic characteristics}

Sixty-four patients with PD were examined; the mean age \pm SD was $71.8 \pm 10.7$ with no significant difference compared with controls (69 \pm 11.3 ); males to females were 52 to $48 \%$, respectively; $59.4 \%$ were from urban areas; and $57.8 \%$ were illiterate. Middle socioeconomic level was recorded in $54.7 \%$. Fourteen percent of cases 
Table 1 Socio-demographic, medical history, and frequency of depression and anxiety among studied groups (patients and controls)

\begin{tabular}{|c|c|c|c|}
\hline Characteristics & $\begin{array}{l}\text { PD patients } \\
N=64\end{array}$ & $\begin{array}{l}\text { Control } \\
N=50\end{array}$ & $P$ value \\
\hline Sex: male/female (number of patients) & $33 / 31$ & $26 / 24$ & 0.964 \\
\hline Age in years, mean $\pm S D$ (years) & $71.8 \pm 10.7$ & $69 \pm 11.3$ & 0.607 \\
\hline Residence: urban/rural (number of patients) & $38 / 26$ & $27 / 23$ & 0.565 \\
\hline Marital status: single/married/divorced or widowed & $8 / 41 / 15$ & $9 / 37 / 4$ & 0.083 \\
\hline Education: illiterate/literate & $37 / 27$ & $28 / 22$ & 0.845 \\
\hline Socioeconomic status (SES): low/middle/high & $26 / 35 / 3$ & $18 / 29 / 3$ & 0.960 \\
\hline Job status: employed/unemployed & $25 / 39$ & $21 / 29$ & 0.751 \\
\hline Smoking (in males): smokers/non-smokers & 20/13 & $16 / 10$ & 0.944 \\
\hline \multicolumn{4}{|l|}{ Risk factors (yes/no) } \\
\hline Diabetes & 9/55 & $5 / 45$ & 0.512 \\
\hline Hypertension & $13 / 51$ & $6 / 44$ & 0.237 \\
\hline Cardiac & $5 / 59$ & $3 / 47$ & 0.707 \\
\hline Depression & 20 & 7 & 0.032 \\
\hline Major depressive disorder & 11 & 4 & 0.150 \\
\hline Minor depression & 9 & 3 & 0.156 \\
\hline Total anxiety disorders & 26 & 5 & $<0.001$ \\
\hline Generalized anxiety disorder & 11 & 2 & 0.028 \\
\hline Panic disorder & 7 & 1 & 0.138 \\
\hline Agoraphobia without panic disorder & 3 & 0 & 0.336 \\
\hline Social phobia & 5 & 2 & 0.401 \\
\hline
\end{tabular}

PD Parkinson's disease

were diabetic, $20.3 \%$ were hypertensive, and $7.8 \%$ were cardiac (Table 1).

Parkinson's disease characteristics of the study subjects

The mean age \pm SD of onset of PD patients was $66.2 \pm$ 9 , and the mean duration of illness was $5.8 \pm 3.2$. About $76.6 \%$ received specific antiparkinsonian treatment, and about $85.7 \%$ of those who received specific treatment had levodopa as their main line of treatment. The mean total UPDRS score was $86.3 \pm 40.7$ and for UPDRS-III was $51.5 \pm 24.4$. The percentage of each stage of Hoehn and Yahr staging was stage $1.5=10.9 \%$, stage $2.5=32.8$, stage $3=42.2 \%$, and stage $4=14.1 \%$.

Prevalence of depression and anxiety in patients with PD Patients with PD had significant higher scores of depressive symptoms than the matched control group $(P=$ 0.032). The frequency of depression among PD patients was $20(31.25 \%)$ with $17.2 \%$ and $14.1 \%$ of those who were depressed having major and minor depression, respectively.

Similarly, patients with PD had significant higher scores of anxiety than the matched control group $(P<0.001)$. The frequency of anxiety disorders among patients with PD was 26 (40.6\%). GAD was the most common anxiety disorders among cases (17.2\%). Overlap between depression and anxiety was recorded in $23.4 \%$ (Table 1 ).

Socio-demographic characteristics among patients with and without depression and in those with and without anxiety

PD with depression was significantly common in those with female gender, low socioeconomic status, and past history of depression $(P=0.004,0.004,<0.001)$ compared with patients without depression, with no significant differences between them in other items. PD patients with anxiety were younger than patients without anxiety $(P<0.001)$ and were higher with those who had previous history of anxiety $(P=0.015)$ (Table 2$)$.

Characteristics of PD patients with depression and anxiety PD patients with depression significantly had advanced disease stage and higher UPDRS scores especially motor symptoms ( $P=0.014$ and $P<0.001$, respectively).

Meanwhile, the age onset of PD for patients with anxiety was younger than patients without anxiety $(P<0.001)$. PD patients with anxiety had significantly advanced disease stage and higher UPDRS scores especially motor (part III) than patients without anxiety $(P=0.038$ and $P<0.001$, respectively) 
Table 2 Socio-demographic, medical, and psychiatric risk factors among patients with and without depression and those with and without anxiety

\begin{tabular}{|c|c|c|c|c|c|c|}
\hline Characteristic & $\begin{array}{l}\text { PD with } \\
\text { depression } \\
N=20\end{array}$ & $\begin{array}{l}\text { PD without } \\
\text { depression } \\
N=44\end{array}$ & $P$ value & $\begin{array}{l}\text { PD with } \\
\text { anxiety } \\
N=26\end{array}$ & $\begin{array}{l}\text { PD without } \\
\text { anxiety } \\
N=38\end{array}$ & $P$ value \\
\hline Age (mean \pm SD) & $69.2 \pm 9.3$ & $73 \pm 11.2$ & 0.190 & $66.1 \pm 9.0$ & $75.7 \pm 10.2$ & $<0.001$ \\
\hline Gender: male/female & $5 / 15$ & $28 / 16$ & 0.004 & $14 / 12$ & $19 / 19$ & 0.762 \\
\hline Residence: urban/rural & $11 / 9$ & $27 / 17$ & 0.631 & $15 / 11$ & $23 / 15$ & 0.821 \\
\hline $\begin{array}{l}\text { Marital status: single/married/divorced/ } \\
\text { widowed }\end{array}$ & $2 / 13 / 5$ & $6 / 28 / 10$ & 0.914 & $3 / 16 / 7$ & $5 / 25 / 8$ & 0.856 \\
\hline Education level: literate/illiterate & $12 / 8$ & $25 / 19$ & 0.811 & $14 / 12$ & $23 / 15$ & 0.595 \\
\hline Socioeconomic status: low/middle/high & $14 / 5 / 1$ & $12 / 30 / 2$ & 0.004 & $10 / 16 / 0$ & $16 / 19 / 3$ & 0.290 \\
\hline Job status: employed/unemployed & $7 / 13$ & $18 / 26$ & 0.653 & $9 / 17$ & $16 / 22$ & 0.546 \\
\hline Smoking (in males): smoker/non-smoker & $3 / 2$ & $16 / 12$ & 0.905 & $9 / 5$ & $11 / 8$ & 0.710 \\
\hline Diabetes: yes/no & $3 / 17$ & $6 / 38$ & 0.884 & $4 / 22$ & $5 / 33$ & 0.801 \\
\hline Hypertension: yes/no & $3 / 17$ & $10 / 34$ & 0.476 & $5 / 21$ & $8 / 30$ & 0.858 \\
\hline Cardiac: yes/no & $1 / 19$ & $4 / 40$ & 0.571 & $2 / 24$ & $3 / 35$ & 0.976 \\
\hline Previous history of depression & 11 & 5 & $<0.001$ & 6 & 10 & 0.768 \\
\hline Previous history of anxiety & 6 & 15 & 0.747 & 13 & 8 & 0.015 \\
\hline
\end{tabular}

PD Parkinson's disease

Cognitive impairment was found to be higher in depressed patients (mean MMSE $=21.5 \pm 4.9$ ) with significant difference compared to non-depressed. Details are illustrated in Table 3.

\section{Correlation analysis results}

Total UPDRS and Hoehn and Yahr scale both have significant positive correlation with HAM-D score $(r=$ $0.576, P<0.0001$, and $r=0.359, P=0.004$ respectively), and MMSE has significant negative correlation with disease duration $(r=-302, P=0.015)$.

Total UPDRS and Hoehn and Yahr staging were significantly correlated with HAM-A scale $(r=0.561$, $P<0.0001$, and $r=0.311, P=0.012$, respectively). Age of onset and age both have significant negative correlation with HAM-A $(r=-0.364, P=0.003$, and $r=-0.344, P=0.005$, respectively). Details are illustrated in Table 4.

Table 3 Comparison between Parkinson's disease patients with and without depression and those with and without anxiety in demographic and clinical criteria

\begin{tabular}{|c|c|c|c|c|c|c|}
\hline Characteristic & $\begin{array}{l}\text { PD with depression } \\
N=20\end{array}$ & $\begin{array}{l}\text { PD without depression } \\
N=44\end{array}$ & $P$ value & $\begin{array}{l}\text { PD with anxiety } \\
N=26\end{array}$ & $\begin{array}{l}\text { PD without anxiety } \\
N=38\end{array}$ & $P$ value \\
\hline Age at onset (mean \pm SD) & $64.4 \pm 7.8$ & $67.1 \pm 9.5$ & 0.155 & $61.2 \pm 7.2$ & $69.7 \pm 8.6$ & $<0.001$ \\
\hline Duration of illness (mean \pm SD) & $5.6 \pm 3.2$ & $5.9 \pm 3.3$ & 0.115 & $5.5 \pm 3.1$ & $5.9 \pm 3.4$ & 0.481 \\
\hline Duration of treatment (mean $\pm \mathrm{SD}$ ) & $4 \pm 2.9$ & $4.6 \pm 2.5$ & 0.292 & $4.1 \pm 2.7$ & $4.8 \pm 2.5$ & 0.066 \\
\hline \multicolumn{7}{|l|}{ Hoehn and Yahr (H Y) stage } \\
\hline Stage 1.5 & 0 & 7 & 0.014 & 1 & 6 & 0.038 \\
\hline Stage 2.5 & 3 & 18 & & 5 & 16 & \\
\hline Stage 3 & 12 & 15 & & 16 & 11 & \\
\hline Stage 4 & 5 & 4 & & 4 & 5 & \\
\hline UPDRS: total score & $122.6 \pm 30.2$ & $69.8 \pm 33.7$ & $<0.001$ & $114.7 \pm 29.8$ & $66.9 \pm 35.7$ & $<0.001$ \\
\hline Mental & $9.1 \pm 2.8$ & $5 \pm 2.1$ & & $8.6 \pm 2.6$ & $4.6 \pm 2.1$ & \\
\hline$A D L$ & $33.4 \pm 10.5$ & $19.8 \pm 10.5$ & & $30.9 \pm 9.8$ & $19.4 \pm 11.5$ & \\
\hline Motor & $73.6 \pm 15.7$ & $41.4 \pm 20.8$ & & $67 \pm 16.5$ & $40.9 \pm 23.3$ & \\
\hline Complications of therapy & $6.6 \pm 5.6$ & $3.6 \pm 3.5$ & & $8.2 \pm 4.7$ & $2 \pm 1.6$ & \\
\hline MMSE & $21.5 \pm 4.9$ & $25.2 \pm 3.8$ & 0.001 & $24.4 \pm 4.1$ & $23.8 \pm 4.7$ & 0.599 \\
\hline
\end{tabular}


Table 4 Correlation between anxiety and depression and various parametric variables

\begin{tabular}{llll}
\hline Pearson correlation & & HAM-D & HAM-A \\
\hline UPDRS total & $r$ value & $.576^{\mathrm{b}}$ & $.561^{\mathrm{b}}$ \\
& $P$ value & .0001 & .0001 \\
Disease duration & $r$ value & -.014 & .025 \\
& $P$ value & .911 & .846 \\
Hoehn and Yahr & $r$ value & $.359^{\mathrm{b}}$ & $.311^{\mathrm{a}}$ \\
& $P$ value & .004 & .012 \\
Age of onset & $r$ value & -.066 & $-.364^{\mathrm{b}}$ \\
& $P$ value & .604 & .003 \\
Age & $r$ value & -.084 & $-.344^{\mathrm{b}}$ \\
& $P$ value & .511 & .005 \\
MMSE & $r$ value & $-.302^{\mathrm{a}}$ & -.021 \\
& $P$ value & .015 & .871 \\
\hline
\end{tabular}

UPDRS Unified Parkinson's Disease Rating Scale, HAM-D Hamilton Depression Rating Scale, HAM-A Hamilton Anxiety Rating Scale, MMSE Mini-Mental State Examination

${ }^{\text {a C}}$ Correlation is significant at the 0.05 level (2-tailed)

${ }^{\mathrm{b}}$ Correlation is significant at the 0.01 level (2-tailed)

\section{Multiple regression analysis results}

All variables which have significant correlation entered hierarchical linear regression to obtain the predictors for depression and anxiety using HAM-D and HAM-A as dependent variables.

For depression, we entered total UPDRS as the first model as it has the strongest correlation; then, we add Hoehn and Yahr scale and MMSE as the second model. UPDRS beta weight was $0.576(t=5.554, P<0.0001)$, and according to model 1, UPDRS accounted for $32 \%$ of variance of depression $\left(f=30.845\right.$, adjusted $\left.R^{2}=0.321\right)$. Despite the fact that Hoehn and Yahr scale in model 2 has borderline significance with beta weight $2.582(t=$ $1.981, P=0.05)$, it is considered in the predicted direction. The whole three variables in model 2 accounted for $33.4 \%$ of the variance for depression $(f=11.99$, adjusted $R^{2}=0.334$ ) which means that Hoehn and Yahr scale and

Table 5 Hierarchical multivariable regression analysis for depression

\begin{tabular}{llllll}
\hline Model & & $\boldsymbol{B}$ & Beta & $\boldsymbol{t}$ & $\boldsymbol{P}$ \\
\hline Model 1 & Constant & 1.472 & & 1.278 & .206 \\
& UPDRS total & .067 & .576 & 5.554 & .0001 \\
Model 2 & Constant & 9.564 & & 1.924 & .059 \\
& UPDRS total & .094 & .810 & 4.694 & .0001 \\
& MMSE & -.132 & -.125 & -1.026 & .309 \\
& Hoehn and Yahr & -2.582 & -.361 & -1.981 & .052 \\
\hline
\end{tabular}

HAM-D is the dependent variable

UPDRS Unified Parkinson's Disease Rating Scale, HAM-D Hamilton Depression Rating Scale, HAM-A Hamilton Anxiety Rating Scale, MMSE Mini-Mental State Examination
MMSE have a little effect for depression prediction (Table 5).

For anxiety, using HAM-A as dependent variable, we entered total UPDRS as the first model as it has the strongest correlation; then, we add age of onset to the second model followed by Hoehn and Yahr to the third model. Although the age variable has a strong negative correlation with HAM-A, it has a strong correlation with age of onset with variance inflation factor (VIF) at 13.433 , so we removed it from the regression equation.

UPDRS in model 1 has beta weight $0.561(t=5.339, P$ $<0.001)$, and it is accounted for $30 \%$ of variance for anxiety $\left(f=28.503\right.$, the adjusted $\left.R^{2}=0.304\right)$. Age of onset at model 2 has beta weight $0.317(t=3.218, P=0.002)$ with about 9\% change in adjusted $R^{2}$ level $(f=21.578$, adjusted $R^{2}=0.39$ ), although Hoehn and Yahr has a good correlation but insignificant prediction to anxiety $(P>0.05)$ (Table 6).

\section{Impact of depression and anxiety on quality of life}

The physical, psychological, and environmental QOL assessed by WHOQOL-BREF questionnaire was significantly worse in PD patients with depression than PD patients without depression especially in physical and psychological domains $(P<0.001)$. Also, physical and psychological QOL was significantly worse in PD patients with anxiety than PD patients without anxiety $(P<0.001)$ (Table 7$)$.

There was a significant negative correlation between overall QOL and HAM-D scale $(r=-0.617, P<0.0001)$ and HAM-A scale $(r=-0.452, P<0.0001)$; Figs. 1 and 2 illustrate the relation between them.

\section{Discussion}

Depression and anxiety are the most disabling nonmotor symptoms in PD patients that have impact on quality of life and affect the global outcome of illness.

Table 6 Hierarchical multivariable regression analysis for anxiety

\begin{tabular}{llllll}
\hline Model & & $\boldsymbol{B}$ & $\boldsymbol{B e t a}$ & $\boldsymbol{t}$ & $\boldsymbol{P}$ \\
\hline Model 1 & Constant & 2.465 & & 1.585 & .118 \\
& UPDRS total & .087 & .561 & 5.339 & .000 \\
Model 2 & Constant & 17.485 & & 3.577 & .001 \\
& UPDRS total & .083 & .533 & 5.421 & .0001 \\
& Age of onset & -.221 & -.317 & -3.218 & .002 \\
Model 3 & Constant & 19.505 & & 3.898 & .0001 \\
& UPDRS total & .117 & .752 & 4.396 & .0001 \\
& Age of onset & -.188 & -.269 & -2.645 & .010 \\
& Hoehn and Yahr & -2.534 & -.266 & -1.553 & .126 \\
\hline
\end{tabular}

HAM-A is the dependent variable

UPDRS Unified Parkinson's Disease Rating Scale, HAM-D Hamilton Depression Rating Scale, HAM-A Hamilton Anxiety Rating Scale, MMSE Mini-Mental State Examination 
Table 7 Impact of depression and anxiety in Parkinson's disease patients on quality of life

\begin{tabular}{|c|c|c|c|c|c|c|}
\hline $\begin{array}{l}\text { QOL domain, } \\
\text { mean } \pm \text { SD }\end{array}$ & $\begin{array}{l}\text { PD patients with } \\
\text { depression, } \\
\text { mean } \pm S D\end{array}$ & $\begin{array}{l}\text { PD patients without } \\
\text { depression, } \\
\text { mean } \pm \text { SD }\end{array}$ & $P$ value & $\begin{array}{l}\text { PD patients } \\
\text { with anxiety, } \\
\text { mean } \pm S D\end{array}$ & $\begin{array}{l}\text { PD patients without } \\
\text { anxiety, mean } \pm S D\end{array}$ & $P$ value \\
\hline QOL: physical domain & $32 \pm 9.1$ & $51.9 \pm 15.6$ & $<0.001$ & $36.9 \pm 12.2$ & $51.7 \pm 16.8$ & 0.001 \\
\hline QOL: psychological domain & $53.8 \pm 17.6$ & $76.5 \pm 10.6$ & $<0.001$ & $58 \pm 17.1$ & $77.3 \pm 11.2$ & $<0.001$ \\
\hline QOL: social domain & $51.4 \pm 26.5$ & $58.75 \pm 25.3$ & 0.347 & $56.8 \pm 26.8$ & $56.2 \pm 25.3$ & 0.939 \\
\hline QOL: environmental domain & $40.4 \pm 17.6$ & $55.4 \pm 20.5$ & 0.006 & $47.7 \pm 20.2$ & $52.8 \pm 21.1$ & 0.410 \\
\hline Overall QOL & $40.5 \pm 13.9$ & $63.2 \pm 11.6$ & $<0.001$ & $48.5 \pm 15.7$ & $61.3 \pm 14.6$ & 0.001 \\
\hline
\end{tabular}

QOL Quality of life, $P D$ Parkinson's disease

The present study evaluated anxiety and depression in PD patients using semi-structured scales.

Nearly $31 \%$ of patients met the DSM-IV criteria for at least one depressive disorder. Forty-one percent of patients met the DSM-IV criteria for at least one anxiety disorder. In two recent Egyptian studies, Shalash and colleagues [26] studied non-motor symptoms in $97 \mathrm{PD}$ patients using BDI-score and found depression frequency at $76.7 \%$. On the other hand, Ragab and colleagues found the prevalence at 47.5\% [27]. Across literature, several studies [7, 28-31] found the prevalence of depression in PD was ranging from 32.6 to $41 \%$. A systematic review conducted by Reijnders et al. reported that $17 \%$ and $22 \%$ of PD patients had MDD and minor depression, respectively [32]. van der Hoek et al. reported that among 256 patients with PD, minor depression and major depression were diagnosed in 36.3\% and $12.9 \%$ of the subjects, respectively, according to BDI-score, with higher prevalence in the more advanced stages of illness with no difference between males and females [33]. This variability of findings may be attributed to the use of different methodologies, size of samples, and genetic variability of study populations.

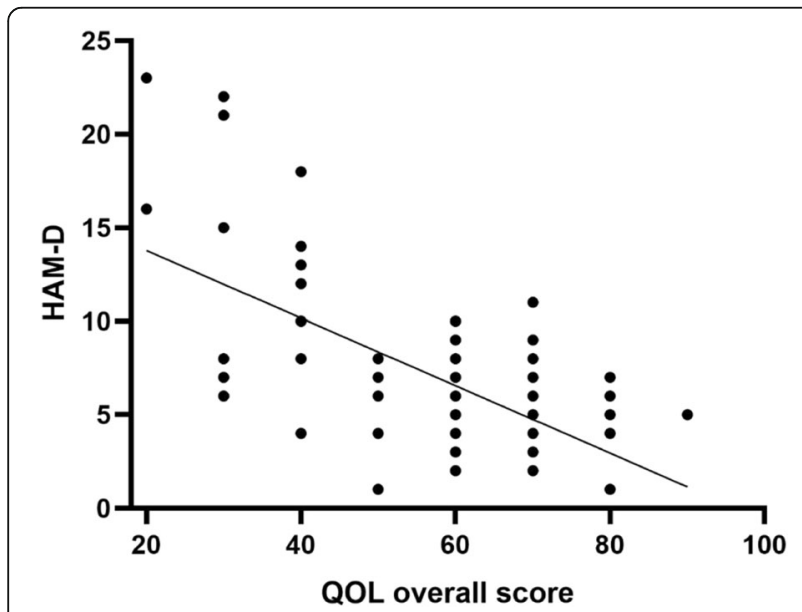

Fig. 1 Correlation between overall QOL and HAM-D scale. Significant moderate negative correlation between overall QOL and HAM-D scale, $r=-0.617, P<0001$
In the present study, out of patients with anxiety disorders, $69.2 \%$ had mild anxiety while the other $30.8 \%$ had moderate to severe anxiety according to HAM-A score, and GAD was the most common anxiety diagnosed. This is in line with prevalence of anxiety among patients with PD by Broen et al. and Leentjens et al. ranging from 24.5 to 46.7 with GAD as the most common single disorder and $31.1 \%$ having mixed anxiety disorder $[34,35]$. In Egypt, Ragab and colleagues report anxiety prevalence around 30\% [27], while in Spain and France the prevalence was $68.7 \%$ and $51 \%$, respectively [30, 31]. On the other hand, a Chinese study found the prevalence was much lower than others around 25.8\% [36].

In the current study, female gender was a risk factor for depression but not for anxiety. Many previous studies showed a significant higher prevalence of depression among female patients with PD [30, 37, 38]. This may be because males are unwilling to exhibit depression, but biological origin rather than psychosocial factors may be the cause. However, other studies did not find any association with gender [39, 40].

Contrary to gender, the present study showed increased prevalence of anxiety among younger PD

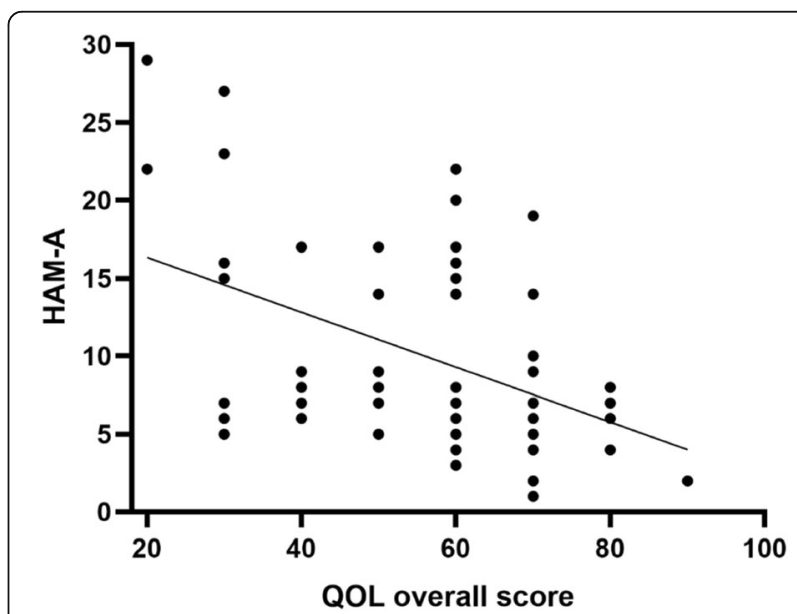

Fig. 2 Correlation between overall QOL and HAM-A scale. Significant weak negative correlation between overall QOL and HAM-A scale, $r$ $=-0.452, P<0001$ 
patients consistent with Zhu and coworkers [41] which may be explained by the fact that the work, financial burden, and care of children are more evident in the younger patients which may be the source of stress and anxiety. However, the mean age in the current study was 71.8 ( \pm 10.7$)$ with a narrow range of ages that makes findings unreliable and further studies comparing young onset and late onset PD are needed.

Previous literatures showed conflicting findings with respect to relationship between age and depression; in some, the older patients were more liable [35, 41, 42] while in others the younger were more depressed [43-47], while many other studies did not confirm any association [48].

In the current study, low socioeconomic status and severity of illness were positively correlated to increased rates of depression. This is feasible with respect to poor quality of life, dependence on others, restricted daily activities, hindering financial burden and inability to cope with regular medical follow-up and costly treatments, etc. This was consistent with the studies of Herath and colleagues and Worku and colleagues $[49,50]$, where the low SES was a risk factor for depression among patients with PD.

In the current study, PD characteristics were studied as predictors for depression and anxiety. Duration of illness and type and duration of treatment did not show any relationship with prevalence of depression or anxiety. Some studies reported more depression in PD patients with longer duration of illness [40, 47] while others showed no relationship [48]. In the present study, the severity of motor symptoms of PD according to UPDRS scoring was positively correlated to both depression and anxiety which could be explained by the increased physical disability, the increased burden of higher dosages of medications, and the need for caregiver; actually, the relationship between depression and motor disability is bimodal, as more severe disability was considered as a risk factor for developing depression in PD patients [43]; on the other hand, depression itself increases the motor disability of PD patients hence more levodopa doses [51].

Our results were consistent with previous literatures [47, 51-53], while other studies did not find such relationship [54]. Supporting this result, a higher stage of illness according to Hoehn and Yahr staging was positively correlated to both depression and anxiety which was consistent with previous literature [47, 52, 55]. Motor disability, gait disturbance, bed restriction, and nonmotor symptoms in late stages of PD predispose to increased risk of depression.

In the current study, previous history of depression or anxiety increased the risk of depression and anxiety, respectively, in patients with PD. Previous studies had supported such finding [56-59].
Of particular interest, PD patients with depression have more cognitive impairment compared with nondepressed patients. There is a complex relationship between cognitive function in one the hand and depression in the other hand with bidirectional implications; depression can lead to worsening cognitive performance, but cognitive impairment is considered as a risk factor for future development of depression [30, 37, 41]. Meanwhile, depressive and anxiety symptoms are also a risk factor for cognitive decline. We found that depressed PD patients had higher potential to have memory problems compared with non-depressed patients. Similar previous studies have found that PD patients with depressive symptoms tended to have lower cognitive function [31-60].

We did not find significant relationship between anxiety and cognition. The relationship between anxiety in $\mathrm{PD}$ and cognition is unclear. Some studies have reported a correlation between anxiety symptoms and cognitive dysfunction [61, 62]. On the other hand, Burn and colleagues [63] reported that cognitive impairment was a significant predictor of depression but not anxiety. Further studies are needed to clarify the relationships between anxiety, depression, and cognitive function in PD.

The current study found both depression and anxiety scores had a significant negative correlation with the QOL scores. Our results were consistent with Shalash and colleagues [26] as they found depression was the primary predictor of QOL impairment in Egyptian patients. The finding is in line with other studies [30, 52, 64] which found that the impact of PD on the QOL measures is independently influenced by non-motor disease aspects. Recent systematic review found that nineteen out of 29 studies confirmed depression is the most important predictor of overall quality of life [65]. Depression impacts the quality of life by direct and indirect effect by impairment of activity of daily living which in turn affects quality of life [66].

Similar studies have demonstrated a correlation between anxiety and QOL in patients with PD [30, 67]. Hanna and Quelhas $[67,68]$ reported that symptoms of anxiety, more so than depression, cognitive status, or motor stage, significantly affected QOL among 38 nondemented patients with mild to moderate motor disability and that anxiety had a stronger impact on QOL in comparison to depression, although anxiety and depression were similarly associated with QOL in the present study.

Psychiatric disorders in PD like depression and anxiety have a major impact on quality of life even in early stages of disease compared to the later stages $[69,70]$. This proves that depression and anxiety are not a reactive response to the disability but an integral part of PD spectrum. 


\section{Limitations}

Main limitations of this study were the relatively small sample size and lack of follow-up of those patients. Larger cohort studies with follow-up are needed to explore variability of psychiatric disorders over time.

\section{Conclusions}

The frequency of depression and anxiety was high which was nearly similar to other literature findings. Those with female gender and low socioeconomic status were more vulnerable to be depressed. Anxiety was recorded more in young ages. Both depression and anxiety cause impairment of quality of life of PD patients in a similar manner.

\section{Abbreviations}

PD: Parkinson's disease; UKPDS: United Kingdom Parkinson's Disease Society; UPDRS: Unified Parkinson's Disease Rating Scale; DSM-IV TR: Diagnostic and Statistical Manual of Mental Disorders 4th Edition revised; HAM-D: Hamilton Depression Rating Scale; HAM-A: Hamilton Anxiety Rating Scale; WHOQOLBREF: The World Health Organization Quality of Life; SES: Socioeconomic status; MMSE: Mini-Mental State Examination; VIF: Variance inflation factor; GAD: Generalized anxiety disorder; QOL: Quality of life; MDD: Major depressive disorder; BDI-score: Beck depression inventory score

\section{Acknowledgements}

Not applicable.

\section{Authors' contributions}

EMK, AA, YE, AF, and AG contributed to the study concept and design, acquisition of data, draft and revision of the report, statistical analyses, and interpretation of data. AFZ, AA, and AG contributed to the case recruitments, acquisition of data, and statistical analyses. EMK, AFZ, and AG contributed to the editing of this report. All authors read and approved the final manuscript.

\section{Funding}

Not applicable.

\section{Availability of data and materials}

The datasets used and/or analyzed during the current study are available from the corresponding author reasonable on request.

\section{Ethics approval and consent to participate}

An informed consent was obtained from all the patients before participating in the study. The protocol was approved in January 2014 by the South Valley Medical School Ethical Review Board, and all participants or relatives gave written informed consent before participation in the study. The ethical approval reference number was not applicable at time of approval of the study. The confidentiality of the patients' information was maintained during all the steps of the study.

\section{Consent for publication}

Not applicable.

\section{Competing interests}

The authors declare that they have no competing interests.

\section{Author details}

${ }^{1}$ Department of Neuropsychiatry, Faculty of Medicine, Assiut University Hospital, Assiut, Egypt. ${ }^{2}$ Neuropsychiatric Department, Faculty of Medicine, Aswan University Hospital, Aswan, Egypt. ${ }^{3}$ Department of Neuropsychiatry, South Valley University Hospital, Qena, Egypt. ${ }^{4}$ Department of Neuropsychiatry, South Valley University Hospital, Qena, Egypt.
Received: 16 October 2020 Accepted: 23 November 2020

Published online: 09 December 2020

\section{References}

1. Postuma RB, Berg D, Stern M, Stern M, Poewe W, Olanow CW, et al. MDS clinical diagnostic criteria for Parkinson's disease. Mov Disord. 2015;30:1591600.

2. Khedr EM, El Fetoh NA, Khalifa H, Ahmed MA, El Beh KM. Prevalence of nonmotor features in a cohort of Parkinson's disease patients. Clin Neurol Neurosurg. 2013;115(6):673-7.

3. Weintraub D, Burn D. Parkinson's disease: the quintessential neuropsychiatric disorder. Mov Disord. 2011;26:1022-31.

4. Hely MA, Morris JG, Reid WG, Trafficante R. Sydney multicenter study of Parkinson's disease: non-L-dopa-responsive problems dominate at 15 years. Mov Disord. 2005;20:190-9.

5. Dobkin RD, Rubino JT, Friedman J, Allen LA, Gara MA, Menza M. Barriers to mental health care utilization in Parkinson's disease. J Geriatr Psychiatry Neurol. 2013;26:105-16.

6. Nilsson FM, Kessing LV, Sorensen TM, Andersen PK, Bolwig TG. Major depressive disorder in Parkinson's disease: a register-based study. Acta Psychiatr Scand. 2002;106:202-11

7. Aarsland D, Påhlhagen S, Ballard CG, Ehrt U, Svenningsson P. Depression in Parkinson disease-epidemiology, mechanisms and management. Nat Rev Neurol. 2012;8:35-47.

8. Burn DJ. Depression in Parkinson's disease. Eur J Neurol. 2002;9:44-54.

9. Meyer PM, Strecker K, Kendziorra K, Becker G, Hesse S, Woelpl D, et al. Reduced a4 $\beta 2{ }^{*}$-nicotinic acetylcholine receptor binding and its relationship to mild cognitive and depressive symptoms in Parkinson disease. Arch Gen Psychiatry. 2009;66(8):866-77.

10. Weintraub D, Mamikonyan E. The neuropsychiatry of Parkinson disease: a perfect storm. Am J Geriatr Psychiatry. 2019;27:998-1018.

11. Gibb WR, Lees AJ. The significance of the Lewy body in the diagnosis of idiopathic Parkinson's disease. Neuropathol Appl Neurobiol. 1989;15:27-44.

12. Hughes AJ, Daniel SE, Kilford L, Lees AJ. Accuracy of clinical diagnosis of idiopathic Parkinson's disease. A clinico-pathological study of 100 cases. JNNP. 1992;55:181-4.

13. Folstein MF, Folstein SE, McHugh PR. "Mini-mental state". A practical method for grading the cognitive state of patients for the clinician. J Psychiatr Res. 1975;12(3):189-98.

14. Farrag A, Farwiz HM, Khedr EH, Mahfouz RM, Omran SM. Prevalence of Alzheimer's disease and other dementing disorders: Assiut-upper Egypt study. Dement Geriatr Cogn Dis. 1998:9(6):323-8.

15. Hoehn MM, Yahr MD. Parkinsonism: onset, progression and mortality. Neurology. 1967;17(5):427-42.

16. Fahn S, Elton R. Members of the UPDRS development committee. In: Fahn S, Marsden CD, Calne DB, Goldstein M, editors. Recent developments in Parkinson's disease, vol. 2. Florham Park: Macmillan Health Care Information; 1987. 153-163:293-304.

17. El-Tawab A. Socioeconomic status scale, faculty of education, department of psychology. Assiut University; 2004.

18. First MB, Spitzer RL, Gibbon M, Williams JBW, Benjamin LS. Structured clinical interview for DSM-IV-clinician version (SCID-CV) (user's guide interview). Washington, DC: American Psychiatric Press; 1997.

19. El Missiry A, Sorour A, Sadek A, Fahy T, Abdel Mawgoud M, Asaad T. Homicide and psychiatric illness: an Egyptian study [MD thesis]. Cairo: Faculty of Medicine, Ain Shams University; 2004.

20. Alhadi AN, Alarabi MA, Alshomrani AT, Shuqdar RM, Alsuwaidan MT, McIntyre RS. Arabic translation, validation and cultural adaptation of the 7 item Hamilton depression rating scale in two community samples. SQUMJ. 2018;18:2.

21. Hallit S, Haddad C, Hallit R, Akel M, Obeid S, Haddad G, et al. Validation of the Hamilton anxiety rating scale and state trait anxiety inventory a and $B$ in Arabic among the Lebanese population. Clin Epidemiol Glob Health. 2019;7(3):464-70

22. Williams J, Hirsch E, Anderson K, Bush A, Goldstein S, Grill S, et al. A comparison of nine scales to detect depression in Parkinson disease: which scale to use? Neurology. 2012;78(13):998-1006.

23. Leentjens AFG, Dujardin K, Marsh L, Richard IH, Starkstein SE, MartinezMartin P. Anxiety rating scales in Parkinson's disease: a validation study of the Hamilton anxiety rating scale, the Beck anxiety inventory, and the hospital anxiety and depression scale. Mov Disord. 2011;26(3):407-15. 
24. Leentjens AFG, Dujardin K, Marsh L, Martinez-Martin P, Richard IH, Starkstein SE, et al. Anxiety rating scales in Parkinson's disease: critique and recommendations. Mov Disord. 2008;23(14):2015-25.

25. Ohaeri JU, Awadalla AW. The reliability and validity of the short version of the WHO quality of life instrument in an Arab general population. Ann Saudi Med. 2009;29(2):98-104.

26. Shalash AS, Hamid E, Elrassas HH, Bedair AS, Abushouk Al, Khamis M, et al. Non-motor symptoms as predictors of quality of life in Egyptian patients with Parkinson's disease: a cross-sectional study using a culturally adapted 39-item Parkinson's disease questionnaire. Front Neurol. 2018;9:357.

27. Ragab OA, Elheneedy YA, Bahnasy WS. Non-motor symptoms in newly diagnosed Parkinson's disease patients. Egypt J Neurol Psychiatr Neurosurg. 2019;55(1):24

28. Zheng J, Yang $X$, Zhao Q, Tian $S$, Huang $H$, Chen $Y$, et al. Association between gene polymorphism and depression in Parkinson's disease: a casecontrol study. J Neurol Sci. 2017:375:231-4.

29. Timmer $M$, van Beek $M$, Bloem B, Esselink R. What a neurologist should know about depression in Parkinson's disease. Pract Neurol. 2017;17:359-68.

30. Chuquilín-Arista F, Álvarez-Avellón T, Menéndez-González M. Prevalence of depression and anxiety in Parkinson disease and impact on quality of life: a community-based study in Spain. J Geriatr Psychiatry Neurol. 2020;33(4): 207-13

31. Nègre-Pagès L, Grandjean $H$, Lapeyre-Mestre M, Montastruc J, Fourrier A, Lépine J, et al. Anxious and depressive symptoms in Parkinson's disease: the French cross-sectional DoPa MiP study. Mov Disord. 2009;25(2):157-66.

32. Reijnders J, Ehrt U, Weber W, Aarsland D, Leentjens A. A systematic review of prevalence studies of depression in Parkinson's disease. Mov Disord. 2008:23(2):183-9.

33. Van der Hoek TC, Bus BA, Matui P, van der Marck MA, Esselink RA, Tendolkar I. Prevalence of depression in Parkinson's disease: effects of disease stage, motor subtype and gender. J Neurol Sci. 2011;310:1-2.

34. Broen M, Narayen N, Kuijf M, Dissanayaka N, Leentjens A. Prevalence of anxiety in Parkinson's disease: a systematic review and meta-analysis. Mov Disord. 2016;31(8):1125-33.

35. Leentjens AFG, Dujardin K, Marsh L, Martinez-Martin P, Richard IH, Starkstein SE. Anxiety and motor fluctuations in Parkinson's disease: a cross-sectional observational study. Parkinsonism Relat Disord. 2012;18:1084-108.

36. Cui S-S, Du J-J, Fu R, Lin Y-Q, Huang P, He Y-C, et al. Prevalence and risk factors for depression and anxiety in Chinese patients with Parkinson disease. BMC Geriatr. 2017:17(1):270.

37. Zhu K, van Hilten JJ, Marinus J. Associated and predictive factors of depressive symptoms in patients with Parkinson's disease. J Neurol. 2016; 263(6):1215-25.

38. Riedel O, Heuser I, Klotsche J, Dodel R, Wittchen H. Occurrence risk and structure of depression in Parkinson disease with and without dementia: results from the GEPAD study. J Geriatr Psychiatry Neurol. 2010;23(1):27-34

39. Reiff J, Schmidt N, Riebe B, Breternitz R, Aldenhoff J, Deuschl G, et al. Subthreshold depression in Parkinson's disease. Mov Disord. 2011;26(9): 1740-3.

40. Farabaugh A, Locascio J, Yap L, Weintraub D, McDonald W, Agoston M, et al. Pattern of depressive symptoms in Parkinson's disease. Psychosomatics. 2009;50(5):448-54.

41. Zhu K, van Hilten JJ, Marinus J. Onset and evolution of anxiety in Parkinson's disease. Eur J Neurol. 2017;24:404-11.

42. Jasinska-Myga B, Putzke JD, Wider C, Wszolek ZK, Uitti RJ. Depression in Parkinson's disease. Can J Neurol Sci. 2010;37(1):61-6.

43. Becker C, Brobert G, Johansson S, Jick S, Meier C. Risk of incident depression in patients with Parkinson disease in the UK. Eur J Neurol. 2010;18(3):448-53.

44. Schrag. Quality of life and depression in Parkinson's disease. J Neurol Sci. 2006;248:151-7

45. Ziropadja L, Stefanova E, Petrovic M, Stojkovic T, Kostic VS. Apathy and depression in Parkinson's disease: the Belgrade PD study report. Parkinsonism Relat Disord. 2012;18:339-42.

46. Fereshtehnejad S-M, Hadizadeh H, Farhadi F, Shahidi GA, Delbari A, Lökk J. Comparison of the psychological symptoms and disease-specific quality of life between early- and typical- onset Parkinson's disease patients. Parkinson's Dis. 2014;819260:1.

47. Zhu J, Lu L, Pan Y, Shen B, Xu S, Hou Y, et al. Depression and associated factors in nondemented Chinese patients with Parkinson's disease. Clin Neurol Neurosurg. 2017:163:142-8.
48. Borek L, Kohn R, Friedman J. Mood and sleep in Parkinson's disease. J Clin Psychiatry. 2006;67(06):958-63.

49. Herath TB, Withana M, Rodrigo C, Gamage R, Gamage C. Prevalence and associations for symptoms of depression in patients with Parkinson's disease: a Sri Lankan experience. Int J Ment Heal Syst. 2016;10:47.

50. Worku DK, Yifru YM, Postels DG, Gashe FE. Prevalence of depression in Parkinson's disease patients in Ethiopia. J Clin Mov Disord. 2014;1:10.

51. Arun MP, Bharath S, Pal PK, Singh G. Relationship of depression, disability, and quality of life in Parkinson's disease: a hospital-based case-control study. Neurol India. 2011;59:185-9.

52. Yamanishi T, Tachibana H, Oguru M, Matsui K, Toda K, Okuda B, et al. Anxiety and depression in patients with Parkinson's disease. Intern Med. 2013:52(5):539-45.

53. Lee Y, Oh JS, Chung SJ, Lee JJ, Chung SJ, Moon H, et al. The presence of depression in de novo Parkinson's disease reflects poor motor compensation. PLoS One. 2018;13(9):e0203303.

54. Kanda F, Oishi K, Sekiguchi K, Kuga A, Kobessho H, Shirafuji T, et al. Characteristics of depression in Parkinson's disease: evaluating with Zung's self-rating depression scale. Parkinsonism Relat Disord. 2008;14:19-23.

55. Piccinni A, Marazziti D, Veltri A, Ceravolo R, Ramacciotti C, Carlini M, et al. Depressive symptoms in Parkinson's disease. Compr Psychiatry. 2012;53:727-31.

56. Dissanayaka NN, Sellbach A, Matheson S. Anxiety disorders in Parkinson's disease: prevalence and risk factors. Mov Disord. 2010;25(7):838-45.

57. Jacob EL, Gatto NM, Thompson A, Bordelon Y, Ritz B. Occurrence of depression and anxiety prior to Parkinson's disease. Parkinsonism Relat Disord. 2010;16:576-81.

58. Leentjens AF, Dujardin K, Marsh L, Martinez-Martin P, Richard $\mathbb{H}_{\text {, Starkstein }}$ SE. Symptomatology and markers of anxiety disorders in Parkinson's disease: a cross-sectional study. Mov Disord. 2011a;26:484-92.

59. Leentjens AF, Moonen AJ, Dujardin K, Marsh L, Martinez-Martin P, Richard $\mathrm{IH}$. Modeling depression in Parkinson disease: disease-specific and nonspecific risk factors. Neurology. 2013;81:1036-43.

60. Dissanayaka NN, Sellbach A, Silburn PA, O'Sullivan JD, Marsh R, Mellick GD. Factors associated with depression in Parkinson's disease. J Affect Disord. 2011b;132(1-2):82-8.

61. Lee WJ, Tsai CF, Gauthier S, Wang SJ, Fuh JL. The association between cognitive impairment and neuropsychiatric symptoms in patients with Parkinson's disease dementia. Int Psychogeriatr. 2012;24:1980-7.

62. Foster PS, Drago V, Mendez K, Witt JC, Crucian GP, Heilman KM. Mood disturbances and cognitive functioning in Parkinson's disease: the effects of disease duration and side of onset of motor symptoms. J Clin Exp Neuropsychol. 2013;35:71-82

63. Burn DJ, Landau S, Hindle JV. Parkinson's disease motor subtypes and mood. Mov Disord. 2012;27:379-86.

64. Menon B, Nayar R, Kumar S, Cherkil S, Venkatachalam A, Surendran K, et al. Parkinson's disease, depression, and quality-of-life. Indian J Psychol Med. 2015;37(2):144-8.

65. Soh SE, Morris ME, McGinley JL. Determinants of health-related quality of life in Parkinson's disease: a systematic review. Parkinsonism Relat Disord. 2011:17:1-9.

66. Lawrence BJ, Gasson N, Kane R, Bucks RS, Loftus AM. Activities of daily living, depression, and quality of life in Parkinson's disease. PLoS One. 2014; 9(7):e102294.

67. Hanna K, Cronin-Golomb A. Impact of anxiety on quality of life in Parkinson's disease. Parkinsons Dis. 2012:2012:640-707.

68. Quelhas R, Costa M. Anxiety, depression and quality of life in Parkinson's disease. J Neuropsychiatr Clin Neurosci. 2009:21:413-9.

69. Jeffrey S. Psychiatric symptoms have greater impact in early vs late PD. Medscape medical news; 2007.

70. Shearer J, Green C, Counsell CE, Zajicek JP. The impact of motor and nonmotor symptoms on health state values in newly diagnosed idiopathic Parkinson's disease. J Neurol. 2011;259(3):462-8.

\section{Publisher's Note}

Springer Nature remains neutral with regard to jurisdictional claims in published maps and institutional affiliations. 